\title{
Hematological Impacts of the Traffic Emissions in Sulaymaniyah Governorate
}

\author{
Dunya Hars Bapir ${ }^{1}$, Salih Ahmed Hama ${ }^{1,2}$ \\ ${ }^{1}$ Department of Biology, College of Science, University of Sulaimani, Kurdistan Region, Sulaymaniyah, Iraq, \\ ${ }^{2}$ Department of Medical Laboratory Sciences, College of Health Sciences, University of Human Development, Kurdistan \\ Region, Sulaymaniyah, Iraq
}

\section{A B S T R A C T}

The current study was achieved to evaluate the essential hematologic impacts of traffic emission. Ninety-six cases were studied that included both exposures and controls. The focal point was on Raparin District in Sulaymaniyah Governorates. A questioner form was depended for collecting the information about each case. Fresh venous blood (5 ml) was collected aseptically from both exposures and controls. Hematologic autoanalyzer (Coulter-Automated Counter) was used for hematologic investigations. It was appeared that the mean leukocyte counts were higher among exposures in comparison to controls; the period of exposure and smoking was significantly effective on total white cells. Lymphocyte counts were significantly declined among exposures. It was appeared that the distance from the emission gas sources, smoking, and period of exposure was significantly effective on the total lymphocyte counts $(P<0.05)$. No valuable effects of traffic emission were noticed on granulocytes in general $(P>0.05)$, although the neutrophil counts were significantly higher among exposure. Moreover, the study revealed that there were noticeable effects of traffic emission, on the total platelet counts between exposures and controls. Finally, the distance from the emission sources was significantly effective on platelet counts among exposures themselves $(P<0.05)$.

Index Terms: Traffic Emission, Hematology, Lymphocytes, Complete Blood Count

\section{INTRODUCTION}

The term pollution was defined as exposing to the harmful pollutants or products in the environment that appeared to have a measurable effect on the man or other animal health as well as on vegetation or other materials [1], [2]. There are five types of pollutants that are hydrocarbon, carbon monoxide, particulate matter, nitrogen dioxide, and sulfur oxides. These tend to be the worst quality content found in Iraqi fuel, which are emitted from the combustion of sulfur containing fossil fuels such as coal, metal smelting, motor vehicle operations, and other industrial processes.

\begin{tabular}{|l|l|}
\hline Access this article online \\
\hline DOI:10.21928/uhdjst.v4n1y2020.pp81-86 & E-ISSN: 2521-4217 \\
P-ISSN: 2521-4209
\end{tabular}

Copyright ( 2020 Dunya Hars Bapir, Salih Ahmed Hama. This is an open access article distributed under the Creative Commons Attribution Non-Commercial No Derivatives License 4.0 (CC BY-NC-ND 4.0)
Urban air pollution is a significant cause of global mortality, pre-mature deaths, which are the causes of seven hundred thousand deaths worldwide according to data from the WHO [3], [4]. Several reports have indicated that exposure to aromatic hydrocarbons such as benzene, toluene, and styrene-butadiene has significant alterations in different hematologic parameters. The noticeable effects include a decline in circulating erythrocytes, hemoglobin (HGB), platelets, total white blood cells (WBCs), and absolute numbers of lymphocytes, as well as neutrophils [4]-[7]. The adverse effects may be on bone marrow and stem cells at both production and differentiation levels. Moreover, it may have effects on Hepcidin's sustained and chronic upregulation that is an iron regulatory protein, which may lead to HGB and red blood cell (RBC) production diminishing. Consequently, anemia can occur [8]-[12]. Leukopenia, thrombocytopenia, and reduction in bone marrow-derived mesenchymal stem cells also may be common side effects [13].

Corresponding author's e-mail: dunyabiologist064@gmail.com/dunya.bapir94@gmail.com

Received: 07-03-2020

Accepted: 23-04-2020

Published: 25-04-2020 
The aims of the current study were to investigate the significant traffic emission impacts of various hematological parameters and to study the effect of some risk factors and their relations to traffic emissions hematologic consequences.

\section{MATERIALS AND METHODS}

Ninety-six persons (males, and females) were studied included (48 exposes and 48 control cases), both sexes involved. The laboratory investigations were done from May 15, 2019, to September 25, 2019. The hematological tests were performed in Azadi Laboratory in Ranya city. Five fresh venous blood were collected from all cases and directly transferred to the lab for investigations. The hematologic examinations were included in the study; leukocyte profiles (total WBC, granulocyte, neutrophil, and lymphocyte) counting. Red cell profiles (RBC, red cell distribution width [RDW], hematocrit [HCT], HGB, mean Cell HGB $\mathrm{MCH}$, mean cell HGB concentration mean corpuscular hemoglobin concentration [MCHC], and mean cell volume [MCV]) counting, as well as the platelet profiles (platelet [PLT], mean platelet volume [MPV], platelet distribution width [PDW], plateletcrit [PCT], and large platelet cell ratio [LPCR]) counting.

Three factors were studied for their relation with the emission impacts on the studied cases, which are exposure period (short-term $-<10$ years - and long-term - more than 10 years); distance from the emission sources $(<500 \mathrm{~m}$ and more than $500 \mathrm{~m}$ ); and finally smoking (smokers and non-smokers).

An automated hematologic analyzer (Coulter; KT6200, of OEM) was depended in achieving the above tests. The obtained data were tabulated and statistical analyses were done using GraphPad prism 6 software (Mann-Whitney $t$-test).

\section{RESULTS AND DISCUSSION}

From the current study, it was appeared that different hematologic parameters were affected negatively by exposure to the chemical compounds produced from the traffic emissions.

\subsection{WBC Measurement WBC}

Studying total WBC counts revealed that the mean value of WBC counts of exposures was 7100 cells $/ \mu 1 \pm 1.5$, whereas the mean value among control cases was ( 6780 cells $/ \mu l \pm 1.8)$, which was lower than that of exposures (Fig. 1). Statistical analysis showed that there were no significant differences between the total WBC counts from exposures and controls $(P>0.05)$.

Due to further analysis, there were significant differences between those with (5-10 years) exposure history (mean $=6700$ cells $/ \mu \mathrm{l} \pm 1$ ), and those with more prolonged exposure $(10-20$ years), (mean $=7400$ cells $/ \mu 1 \pm 1.9)$ $(P<0.05)$. Furthermore, significant differences were observed among smoker exposures (mean $=7500$ cells $/ \mu \mathrm{l}$ $\pm 2.1)$ and non-smoker exposures (mean $=6800 \mathrm{cell} / \mu \mathrm{l} \pm 1.2$ ) $(P<0.05)$. Moreover, it was reported by the current study that the total numbers of lymphocytes were also affected by exposure to traffic emissions. It was noticed that the mean value of the lymphocyte counts among exposures was lower (1100 cells/ $\mu \mathrm{l} \pm 3.7)$, when compared with controls (1900 cells/ $\mu \mathrm{l} \pm 3.9)$. There was a significant difference between exposures and controls regarding the mean value of lymphocyte count levels $(P<0.05)$ (Fig. 1). The mean value of lymphocytes among exposures whose home distances about 100-200 $\mathrm{m}$ far from traffic contamination sources were 1052 cells $/ \mu \mathrm{l} \pm 3$.6, while it was slightly higher $(1107$ cells $/ \mu \mathrm{l}$ 土3.7) among exposures whose home distance was far from the first group (500-1000 m) from the sources of traffic gases. It was appeared that the distance from the emission

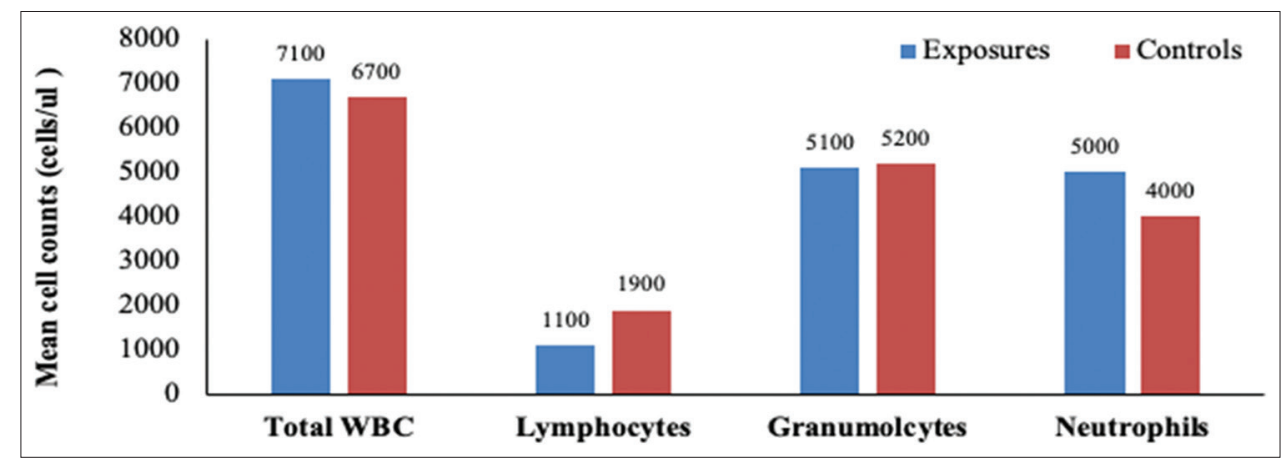

Fig. 1. Leukocyte measurements for traffic emission exposures and controls. 
gas sources has a significant effect on the mean values of lymphocytes among exposures themselves $(P<0.05)$.

The total lymphocyte counts among exposed smokers were 1002 cells $/ \mu 1 \pm 3.5$, whereas among non-smoker exposures were higher $(1161 \mathrm{cell} / \mu \mathrm{l} \pm 3.8)$, the statistical analyses indicated that there were valuable effects of smoking on the lymphocyte counts especially when integrated with traffic emission gases $(P<0.05)$. In addition, the effects of the duration of emission exposure on lymphocytes counts showed that the mean value for exposures with about $5-10$ years of exposing history was 1137 cells $/ \mu 1 \pm 3.4$. For those with more prolonged exposure history (10-20 years) lymphocytes were relatively lower (1056 cells $/ \mu 1 \pm 3.7)$, which indicated that the exposure duration plays a significant effect on the total lymphocyte counts $(\mathrm{P}<0.05)$.

The lower levels of lymphocyte count among exposures may be due to the toxic effects of the chemical contents of the traffic emissions. Similar observations were recorded by other investigators who found that the mean value of lymphocyte counts was reduced as a result of exposure to chemicals raised from fuel-burning [9]. Integration of the smoking effects with emission gases among exposures confirmed the impact of traffic emissions of the WBCs in general and on lymphocyte numbers, especially the mean value of lymphocytes was declined among non-smokers and significantly different from controls.

The observations reported by the current study were parallel to the results mentioned by other investigators [10] who noticed a decline in the total numbers of white cells and lymphocytes among mice, which were exposed to the traffic emissions. Changes in granulocyte counts also were studied. The mean value of granulocytes was 5100 cells $/ \mu l \pm 7.8$ among exposures, and 5200 cells $/ \mu 1 \pm 9.7$ among controls. No significant difference was seen between exposures and controls considering granulocytes $(P>0.05)$ (Fig. 1). No valuable effects of smoking and exposure duration were reported $(P>0.05)$, which may indicate that any decline in the granulocyte numbers was not due to the smoking effects, as in the case of lymphocytes. Unlike the above observations, the mean value of neutrophil counts was significantly higher among exposed cases (5100 cells $/ \mu l \pm 1$ ) when compared to that of control cases (4000 cells $/ \mu \mathrm{l} \pm 9.4$ ) (Fig. 1). Smoking and exposure periods showed no noticeable effects among exposures themselves $(P>0.05)$. The current observations relatively confirm the impact of chemical products of the traffic emission, especially when the effects of smoking were adverse, as other investigators talked about the negative effects of smoking on blood parameters, including granulocyte. Different investigators reported that the neutrophil count was raised among emission exposures when they compared their observations to the control groups [5].

Moreover, the results of the current study were parallel to the observations recorded by other study that showed higher neutrophil counts exposures when compared to controls [6].

\subsection{RBCs Measurement RBC}

In general, the total numbers of RBCs were almost similar between exposures $(5700 \times 102$ cells $/ \mu 1 \pm 0.83)$ and controls $(5600 \times 102$ cells $/ \mu \mathrm{l} \pm 1)$, and no valuable variations were seen between them $(P>0.05)$ (Fig. 2). The RBC counts for those whose home was (100-200 $\mathrm{m}$ ) far from the sources of traffic emissions was $(5400 \times 102$ cells $/ \mu \mathrm{l} \pm 0.5)$, while it was higher for those whose home was more far (500-1000 m) that was $(5900 \times 102$ cells $/ \mu 10.9)$. Smoker exposures showed lower RBC counts $(5500 \times 102$ cells $/ \mu 1 \pm 0.7)$ when compared with non-smoker exposures $(5800 \times 102$ cells $/ \mu 1 \pm 1.2)$, although it was not significant $(P>0.05)$. It was noticed that RBC count for exposures with (5-10 years) exposure history was higher $(5600 \times 102$ cells $/ \mu 1 \pm 1.1)$, in compared

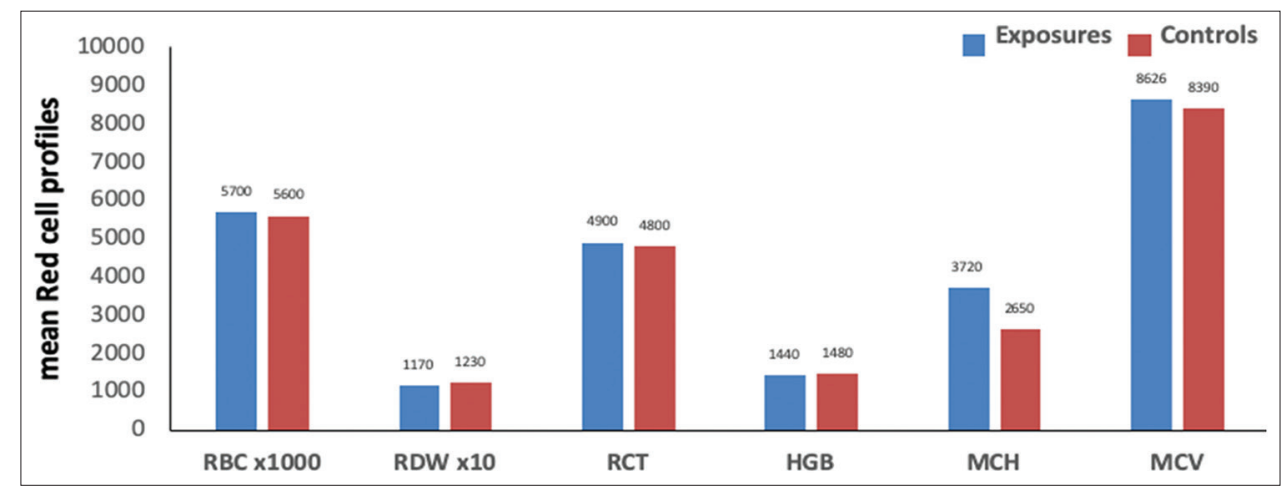

Fig. 2. Mean values of red blood cells for traffic emission exposures and controls. 
to those with more prolonged exposure history (10-20 years) $(5400 \times 102$ cells $/ \mu 1 \pm 0.81)$. However, the differences were not valuable $(P>0.05)$. Among the factor that may explain the above observation may be due to the sample collection season (summer), where the traffic gases may be less effective on exposures compare to cold and dry weather. However, other scientific works reported significant effects of traffic gases on RBC counts and showed elevated RBC counts among exposures does not agree with the current observations [8]. Moreover, another factor may play a role, which is the presence of relatively low levels of $\mathrm{PM}_{2.5}$ in the Iraq fuel, as previously noticed that the high $\mathrm{PM}_{2.5}$ may be responsible for elevations in RBC counts [8], [9], [15].

The RDW for exposures was lower $(11.7 \%, \pm 0.74)$ when compared with that of controls $(12.3 \%, \pm 0.94)$, although it was not significant $(P>0.05)$ (Fig. 2). It was noticed that smoking, home distance, and exposure duration have no significant effects on RDW for exposures themselves $(P>0.05)$. The low levels of RDW in the current study may be due to the slight reductions in RBC counts, especially the RDW can be considered as a marker for RBC counts and sizes. The results of the current study not agreed with the previous reported by other investigators who showed decline RBC counts significantly [22].

Furthermore, it was reported that the HCT for exposures $(49 \%, \pm 0.98)$ was not different significantly from that of controls $(48 \%, \pm 0.76)(P>0.05)$ (Fig. 2). Statistical analysis indicated that smoking, home distance, and exposure duration have no significant effect on HCT $(P>0.05)$. The changes in the HCT among exposures may be due to the limited effects of traffic emission, as mentioned earlier, especially HCT that can reflect alterations in red cell count and functions. The current observations were not agreed with the results reported by other studies that showed the elevated HCT among traffic emission exposures [8], [15]. Moreover, results showed that emission exposure has no significant effects on $\mathrm{Hb}$ of exposures $(14.4 \mathrm{~g} \% \pm 4)$ compared to controls $(14.8 \mathrm{~g} \% \pm 2.9)(P>0.05)$ (Fig. 2). Smoking, home distance, and exposure duration showed no valuable effects on $\mathrm{Hb}(P>0.05)$. The current results indicated that due to non-valuable decline in $\mathrm{Hb}$, the value of HCT was not changed significantly $(P>0.05)$. The above results were not agreed with the studies that reported by other researchers in the past that observed the pollutants could lead to anemic conditions, which consequently cause a reduction in HCT [6], [11], [23]. Although the results of the current study were supported to the observations that reported by some investigators who studied the effects of emissions on traffic polices and in Pakistan, and claimed that the traffic emission has no significant effects of HGB HB. While they reported that smoking was effective on $\mathrm{HB}$, which was not agreeing with the current observation [16], [17].

$\mathrm{MCH}$ also was among the hematologic parameters which were not significantly varied between exposures and controls $(P>0.05)$. Furthermore, it was noticed that smoking, home distance, and exposure duration have no valuable effects on $\mathrm{MCH}$ and MCV $(P>0.05)$. Similarly, the observations were recorded for MCHC $(P>0.05)$ (Fig. 2), which was agreed with results obtained in a study done on mice in the past considering MCHC, where the level was reduced [14]. As our statement, the lack of effects of the traffic of emission on the vast majority of RBC profiles may be due to the saturated environment with $\mathrm{O}_{2}$, especially the study area is rich in forest

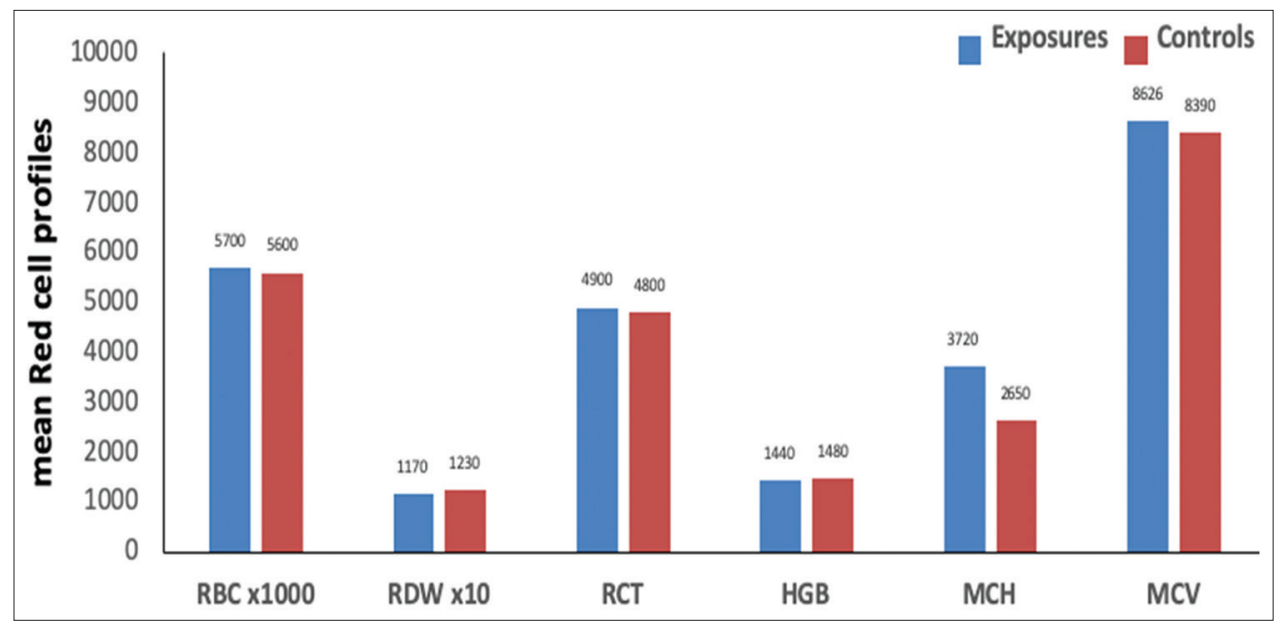

Fig. 3. Mean value of platelet profile for traffic emission exposures and controls. 
and green spaces are at an excellent level. Low levels of $\mathrm{O}_{2}$ can negatively affect $\mathrm{RBC}$ profiles; especially there is a strong relation between RBC and oxygen transportation.

\subsection{Platelet Measurement PLT}

The mean values of platelet count among exposures were higher (1800 cells $/ \mu \mathrm{l} \pm 6.5)$ than that of controls $(1690$ cells $/ \mu \mathrm{l}$ $\pm 3.9)$. When the results analyzed, it has appeared that significant differences were found among exposures and controls regarding platelet counts $(P<0.05)$ (Fig. 3). Moreover, it was concluded that home distance and exposure duration have significant effects on platelet counts, respectively $(P<0.05)$. Smoking showed no valuable effects, which may confirm that all outcomes are due to the long-term exposure to the chemical components of traffic emission, not to the smoking contents. Other researcher found similar results on experimental animals and humans [18], [19], [20], [21]. They suggested elevation in platelet counts concerning emission air pollutants.

The current study revealed that there were no noticeable differences between exposures and controls regarding MPV $(P>0.05)$. Furthermore, it has appeared that home distance, smoking, and exposure duration have no significant effects of MPV $(P>0.05)$ (Fig. 3). Similarly, no valuable variations were observed between exposures and controls regarding PDW Smoking, home distance, and exposure duration showed no noticeable effects on PDW $(P>0.05)$ (Fig. 3), which might be due to the relations of changes in both MPV and PDW [24]. In addition, it was concluded from the current study that traffic emission has no significant effect on PCT and LPCR $(P>0.05)$. This study revealed that smoking, home distance, and exposure duration showed no valuable effects on each of PCT and LPCR $(P>0.05)$ (Fig. 3). In a study, it was noticed that the LPCR effects due to chemical exposure have a significant role in the discrimination between hyperdestructive and hypo-productive thrombocytopenia [25]. However, the PCT levels were fewer, especially among traffic emission exposures; however, it may increase in acute cholecystitis patients with PDW and lowered MPV [24].

\section{CONCLUSION}

Traffic emission gases showed no significant effects on the vast majority of the hematologic parameters, although, valuable elevation has been seen in neutrophils and platelets due to the traffic emission. The results of the current study suggested links between inflammatory and cardiovascular diseases among emission exposures. Future researches must be considered to investigate these relations.

\section{REFERENCES}

[1] M. Franchini and P. M. Mannucci. "Thrombogenicity and cardiovascular effects of ambient air pollution". Journal of Blood, vol. 118, no. 9, p. 2405, 2011.

[2] R. Khan and A. Agarwal. "Modulatory effect of Vitamine E and C on nitrogen dioxide induced hematotoxicity in both the sexes of wistar rats". International Journal of Interdisciplinary Research, vol. 3, no. 3, pp. 46-50, 2016.

[3] N. Boussettaa, S. Abedelmalekc, H. Mallekd, K. Alouie and N. Souissiaa. "Effect of air pollution and time of day onperformance, heart rate hematologicalparameters and blood gases, following theYYIRT-1 in smoker and non-smoker soccerplayers". Science and Sports, vol. 33, no. 6, pp. 1-14, 2018.

[4] P. Ahlawat. "Effect of sulphur dioxide exposure on haematological parameters in albino rats". Journal of Scientific and Engineering Research, vol. 3, no. 6, pp. 58-60, 2016.

[5] C. Tan, Y. Wang, M. Lin, Z. Wang, L. He, Z. Li, Li, Y and K. Xu. "Longterm high air pollution exposure induced metabolic adaptations in traffic policemen". Environmental Toxicology and Pharmacology, vol. 58, no. 16, pp. 156-162, 2018.

[6] R. M. Kartheek and M. David. "Modulations in haematological aspects of wistar rats exposed to sublethal doses of fipronil under subchronic duration". Journal of Pharmaceutical, Chemical and Biological Sciences, vol. 5, no. 3, pp. 187-194, 2017.

[7] C. Jephcote and A. Mah. "Regional inequalities in benzene exposures across the European petrochemical industry: A Bayesian multilevel modelling approach". Environment International, vol. 132, no. 104812, pp. 1-17, 2019.

[8] Bahaoddini and M. Saadat. "Hematological changesdue to chronic exposure to natural gasleakage in polluted areasof Masjid-i-Sulaiman (Khozestan province, Iran)". Ecotoxicology and Environmental Safety, vol. 58, no. 2, pp. 273-276, 2004.

[9] Kamal, A. Cincinelli, T. Martellini and R. N. Malik. "Linking mobile source-PAHs and biological effects in traffic police officers and drivers in Rawal pindi (Pakistan)". Ecotoxicology and Environmental Safety, vol. 127, pp. 135-143, 2016.

[10] G. M. Farris, S. N. Robinson, B. A. Wong, V. A. Wong, W. P. Hahn and R. Shah. "Effects of benzene on splenic, thymic, and femoral lymphocytes in mice". Toxicology, vol. 118, no. 2-3, pp. 137-148, 1997.

[11] T. Honda, C. V. Puna, J. Manjourides and H. Suhb. "Anemia prevalence and hemoglobin levels are associated with long-term exposure to air pollution in an older population". Environment International, vol. 101, no. 4, pp. 125-132, 2017.

[12] A. Masih, A. Lall, A. Taneja and R. Singhvi. "Exposure profiles, seasonal variation and health risk assessment of BTEX in indoor air of homes at different microenvironments of a terai province of northern India". Chemosphere, vol. 176, no. 2, pp. 8-17, 2017.

[13] M. Abu-Elmagd, M. Alghamdi, M. Shamy, M. Khoder, M. Costa, M. Assidi, R. Kadam, H. Alsehli, M. Gari, P. N. Pushparaj, G. Kalamegam and M. H. Al-Qahtani. "Evaluation of the effects of airborne particulate matter on bone marrow-mesenchymal stem cells (BM-MSCs): Cellular, molecular and systems biological approaches". International Journal of Environmental Research and Public Health, vol. 14, no. 4, p. 440, 2017.

[14] J. Reisa and S. Martel. "Acute exposure guideline levels for selected airborne. In: Acute Exposure Guideline Levels, National Academy of Sciences/National Research Council (US) Committee, Washington DC, USA, p. 178, 2014. 
[15] L. Ton. "Platelet neutrophil interactions as drivers of inflammatory and thrombotic disease". Cell and Tissue Research, vol. 371, pp. 567-576, 2018.

[16] E. Wigenstama, L. Elfsmarka, A. Buchta and S. Jonassona. "Inhaled sulfur dioxide causes pulmonary and systemic inflammation leading tochemical-induced lung injury". Toxicology, vol. 368-369, no. 4, pp. 28-36, 2016.

[17] Ö. Etlik and A. Tomur. "The oxidant effects of hyperbaric oxygenation and air pollution in erythrocyte membranes (hyperbaric oxygenation in air pollution)". European Journal of General Medicine, vol. 3, no. 1, pp. 21-28, 2006.

[18] P. Poursafa, R. Kelishadi, A. Amini, Amini, A. M. Amin, M. Lahijanzadeh and M. Modaresi. "Association of air pollution and hematologic parameters in children and adolescents". Jornal de Pediatria, vol. 87, no. 4, pp. 350-356, 2011.

[19] Gorriz, S. Llacuna, M. Riera and J. Nadal. "Effects of air pollution on hematological and plasma parameters in apodemus sylvaticus and mus musculus". Archievs of Environmental Contamination and Toxicology, vol. 31, no. 1, pp. 153-158, 1996.

[20] G. L. Walter. "Effects of carbon dioxide inhalation on hematology, coagulation, and serum clinical chemistry values in rats". Toxicologic Pathology, vol. 27, no. 2, pp. 217-225, 1999.
[21] Q. Sun, X. Hong and L. E. Wold. "Cardiovascular effects of ambient particulate air”. Circulation Journal, vol. 121, no. 25, pp. 2755$2765,2010$.

[22] M. Kargarfard, A. Shariat, B. Shaw, I. Shaw, T. Lam, A. Kheiri, A. Eatemadyboroujeni and S. M. Tamrin. "Effects of polluted air on cardiovascular and hematological parameters after progressive maximal aerobic ex". Lung Journal, vol. 193, no. 2, pp. 275-281, 2015.

[23] M. Nikolić, D. Nikić and A. Stanković. "Effects of air pollution on red blood cells in children". Polish Journal of Environmental Study, vol. 17, no. 2, pp. 267-271, 2008.

[24] M. Zain and S. Aitte. "Study of changes in blood parameters and calculation of PCT, MPV and DPW for the platelets of laboratory females and males of albino mice during exposure to doses of pyrethriodpesticide (alphacypermethrin)". IOSR Journal of Pharmacy and Biological Sciences, vol. 14, no. 2, pp. 71-78, 2019.

[25] Y. Budak, M. Polat and K. Huysal. "The use of platelet indices, plateletcrit, mean platelet volume and platelet distribution width in emergency non-traumatic abdominal surgery: A systematic review". Biochemical Medicine (Zagreb), vol. 26, no. 2, pp. 178193, 2016. 